\title{
Recovery Fosfat dan Amonium Menggunakan Teknik Presipitasi Struvite
}

\author{
Widya Prihesti Iswarani dan IDAA Warmadewanthi \\ Departemen Teknik Lingkungan, Fakultas Teknik Sipil Lingkungan dan Kebumian, Institut Teknologi Sepuluh \\ Nopember (ITS) \\ e-mail:warma@its.ac.id
}

\begin{abstract}
Abstrak — Limbah industri pupuk yang mengandung fosfat dan amonium dengan konsentrasi tinggi dapat diolah menggunakan teknik presipitasi struvite. Penelitian ini dilakukan dengan sistem batch. pH diatur pada pH 8; 8,2; dan 8,5. Rasio molar yang digunakan adalah 1,5:15:1; 2:15:1; 2,5:15:1; dan 3:15:1 dengan presipitan $\mathrm{MgCl}_{2}$. Running presipitasi dilakukan dengan kecepatan pengadukan $158 \mathrm{rpm}$ selama 60 menit dan dilanjutkan dengan sedimentasi selama 30 menit. Hasil penelitian menunjukkan $\mathrm{pH}$ optimum untuk presipitasi struvite adalah 8,5 dan rasio molar $\left[\mathrm{Mg}^{2+}\right]:\left[\mathrm{NH}_{4}{ }^{+}\right]:\left[\mathrm{PO}_{4}{ }^{3-}\right]$ optimum adalah 1,5:15:1. Konsentrasi awal amonium adalah 12.282,60 $\mathrm{mg} / \mathrm{L}$ dan residual amonium adalah $8.215,28 \mathrm{mg} / \mathrm{L}$. Konsentrasi awal fosfat adalah $4180,33 \mathrm{mg} / \mathrm{L}$ dan residual fosfat adalah 1,90 $\mathrm{mg} / \mathrm{L}$.
\end{abstract}

Kata Kunci-Amonium, Fosfat, Presipitasi, Struvite,

\section{PENDAHULUAN}

B ATUAN fosfat adalah sumber daya alam yang tidak dapat diperbarui. Berdasarkan jumlah kebutuhan fosfat saat ini, diperkirakan batuan fosfat hanya akan bertahan dalam waktu 30 sampai 300 tahun [1]. Untuk menjaga stabilitas fosfat, diperlukan sumber fosfat baru yang berkelanjutan [2]. Air limbah yang kaya dengan fosfat dapat digunakan sebagai sumber sekunder untuk memproduksi pupuk fosfat [3]. Air limbah industri pupuk yang memiliki konsentrasi fosfat dan amonium yang tinggi dapat dimanfaatkan untuk direcovery dalam bentuk struvite. Struvite adalah endapan yang terbentuk dari reaksi magnesium, amonium, dan fosfat dengan rasio molar yang sama membentuk $\mathrm{MgNH}_{4} \mathrm{PO}_{4} \cdot 6 \mathrm{H}_{2} \mathrm{O}$ [4]. Dalam proses recovery fosfat sebagai struvite diperlukan sumber magnesium tambahan seperti $\mathrm{MgCl}_{2}$ dan $\mathrm{MgSO}_{4}$ [5]. Pada penelitian ini digunakan sumber magnesium $\mathrm{MgCl}_{2}$ karena memiliki kelarutan yang tinggi dan memiliki kemampuan removal fosfat yang baik [6].

Presipitasi struvite dipengaruhi oleh beberapa faktor yaitu rasio molar, $\mathrm{pH}$, kecepatan pengadukan, laju dan waktu aerasi, dan keberadaan ion pengotor. Rasio molar memiliki dampak besar terhadap komposisi presipitat struvite. Penambahan magnesium yang berlebih dapat meningkatkan efisiensi removal pada proses ini, akan tetapi juga dapat menurunkan kemurnian struvite yang terbentuk [7]. $\mathrm{pH}$ merupakan faktor penting dalam pembentukan struvite karena berpengaruh pada kelarutan dan sifat termodinamikanya [8]. Penelitian ini akan dilakukan secara batch untuk menentukan kemampuan teknik presipitasi untuk recovery fosfat dari limbah cair PT Petrokimia Gresik dalam bentuk struvite. Permodelan $\mathrm{pH}$ dan rasio molar $\left[\mathrm{Mg}^{2+}\right]:\left[\mathrm{NH}_{4}{ }^{+}\right]:\left[\mathrm{PO}_{4}{ }^{3-}\right]$ akan dilakukan terlebih dahulu menggunakan aplikasi PHREEQC Interactive (versi 3.3.12).
Setelah didapatkan variasi optimum, dilakukan pengujian di laboratorium untuk menentukan pengaruh $\mathrm{pH}$ dan rasio molar $\left[\mathrm{Mg}^{2+}\right]:\left[\mathrm{NH}_{4}{ }^{+}\right]:\left[\mathrm{PO}_{4}{ }^{3-}\right]$ optimum pada proses recovery fosfat dalam bentuk struvite.

\section{METODE PENELITIAN}

\section{A. Penelitian Pendahuluan}

Penelitian pendahuluan dilaksanakan untuk mengetahui karakteristik limbah cair industripupuk. Parameter yang akan diuji pada penelitian pendahuluan adalah COD, alkalinitas, amonium, fosfat, pH, DO, silika, fluor, kalsium, magnesium, aluminium, dan sulfat. Selain menguji karakteristik limbah cair industri pupuk, penelitian pendahuluan juga dilakukan untuk memilih variasi yang digunakan dalam penelitian. Untuk memilih variasi ini, dilakukan permodelan menggunakan aplikasi PHREEQC Interactive versi 3.3.12. Prediksi pembentukan spesies struvite dilakukan dengan cara memasukkan nilai Ksp struvite, karakteristik eksisting limbah, $\mathrm{pH}$, dan variasi rasio molar $\left[\mathrm{Mg}^{2+}\right]$ : $\left[\mathrm{NH}_{4}{ }^{+}\right]$: $\left[\mathrm{PO}_{4}{ }^{3-}\right]$. Input variasi $\mathrm{pH}$ ke aplikasi PHREEQC adalah $\mathrm{pH}$ 7-9. Input variasi rasio molar $\left[\mathrm{Mg}^{2+}\right]:\left[\mathrm{NH}_{4}{ }^{+}\right]:\left[\mathrm{PO}_{4}{ }^{3-}\right]$ adalah mulai dari rasio molar 1:15:1 sampai dengan 4:15:1 dengan kenaikan rasio molar $\mathrm{Mg}^{2+}$ sebesar 0,5 .

\section{B. Penelitian Utama}

Reaktor yang digunakan dalam penelitian ini adalah jar test apparatus dan reaktor akrilik yang dilengkapi dengan kran untuk mengeluarkan presipitat. Pengoperasian reaktor dilakukan dengan sistem batch. Sampel limbah sebanyak $1 \mathrm{~L}$ dimasukkan ke dalam reaktor akrilik bervolume 1,2 L, selanjutnya ditambahkan $\mathrm{MgCl}_{2}$ ke dalam sampel untuk mendapatkan rasio molar $\left[\mathrm{Mg}^{2+}\right]:\left[\mathrm{NH}_{4}{ }^{+}\right]$: $\left[\mathrm{PO}_{4}{ }^{3-}\right]$ sesuai hasil permodelan. $\mathrm{pH}$ akan diatur hingga tercapai $\mathrm{pH}$ optimum sesuaihasil permodelan. Setelah penambahan $\mathrm{MgCl}_{2}$, jar test apparatus dinyalakan dan diatur pada kecepatan pengadukan yang digunakan mengacu pada penelitian [9] yaitu $158 \mathrm{rpm}$ dan waktu pengadukan selama 60 menit. Pengadukan dilanjutkan dengan sedimentasi selama 30 menit. Selama proses presipitasi berlangsung, $\mathrm{pH}$ akan terus dipantau menggunakan $\mathrm{pH}$ meter tipe $\mathrm{pH}-\mathrm{pen}$. Parameter yang diuji adalah $\mathrm{pH}$, residual fosfat, dan residual amonium.

\section{HASIL DAN PEMBAHASAN}

\section{A. Karakteristik Air Limbah}

Pada penelitian ini digunakan air limbah industri pupuk. Air limbah yang digunakan adalah air limbah tanpa 
pengenceran ataupun pencampuran. Rasio molar $\left[\mathrm{NH}_{4}{ }^{+}\right]:\left[\mathrm{PO}_{4}{ }^{3-}\right]$ adalah 15:1. Rasio molar ini di-input ke aplikasi PHREEQC untuk memperoleh variasi penelitian. Tabel 1 menunjukkan karakteristik air limbah industripupuk.

Tabel 1.

Hasil Karakterisasi Air Limbah Industri Pupuk

\begin{tabular}{lcr}
\hline \hline \multicolumn{1}{c}{ Parameter } & Satuan & \multicolumn{2}{c}{ Nilai } \\
\hline COD & $\mathrm{mg} / \mathrm{L}$ & 670,00 \\
Amonium & $\mathrm{mg} / \mathrm{L}$ & 12282,60 \\
Fosfat & $\mathrm{mg} / \mathrm{L}$ & 4180,33 \\
Fluorida & $\mathrm{mg} / \mathrm{L}$ & 941,97 \\
Kalsium & $\mathrm{mg} / \mathrm{L}$ & 0,06 \\
Magnesium & $\mathrm{mg} / \mathrm{L}$ & 0,11 \\
Silika & $\mathrm{mg} / \mathrm{L}$ & 0,83 \\
Aluminium & $\mathrm{mg} / \mathrm{L}$ & 1,15 \\
Sulfat & $\mathrm{mg} / \mathrm{L}$ & 8858,00 \\
Alkalinitas $\left(\mathrm{HCO}_{3}{ }^{-}\right.$ & $\mathrm{mg} / \mathrm{L}$ & 5280,00 \\
CaCO & \\
DO & & 0,00 \\
$\mathrm{pH}$ & $\mathrm{mg} / \mathrm{L}$ & 8,60 \\
\hline \hline
\end{tabular}

B. Hasil Prediksi Variasi pH dan Rasio Molar $\left[\mathrm{Mg}^{2+}\right]:\left[\mathrm{NH}_{4}^{+}\right]:\left[\mathrm{PO}_{4}^{3-}\right]$

Variasi $\mathrm{pH}$ dan rasio molar dipilih dengan pertimbangan banyaknya presipitat struvite yang terbentuk dan konsentrasi residual fosfat serta amonium yang terkecil. Berdasarkan prediksi presipitat yang terbentuk, maka variasi $\mathrm{pH}$ yang digunakan dalam penelitian ini adalah $8 ; 8,2$; dan 8,5 . $\mathrm{pH}$ ini adalah $\mathrm{pH}$ yang akan dipertahankan dalam keadaan setimbang ( $\mathrm{pH}$ equilibrium). Pemilihan variasi $\mathrm{pH}$ ini dikarenakan pada $\mathrm{pH} 8 ; 8,2$; dan 8,5 terbentuk paling banyak presipitat struvite dibandingkan pada $\mathrm{pH}$ lain. Selain itu, pada $\mathrm{pH} 8 ; 8,2$; dan 8,5 efisiensi removal amonium lebih tinggi dibandingkan pada $\mathrm{pH}$ lain pada range $\mathrm{pH}$ 7-9. Pada nilai $\mathrm{pH}$ $7-9$, efisiensi removal fosfat sudah mencapai $99 \%$ sehingga pemilihan $\mathrm{pH}$ hanya didasarkan pada banyaknya struvite yang terbentuk serta efisiensi removal amonium.

\section{Pengaruh pH terhadap Efisiensi Removal Fosfat dan Amonium}

Derajat keasaman atau $\mathrm{pH}$ merupakan faktor penting dalam pembentukan struvite. Nilai $\mathrm{pH}$ akan mempengaruhi kelarutan struvite dan sifat termodinamikanya [8]. Kenaikan $\mathrm{pH}$ dapat meningkatkan laju nukleasi kristal struvite [10]. Selama proses presipitasi akan terjadi penurunan $\mathrm{pH}$ akibat penambahan reagen $\mathrm{MgCl}_{2}$ dan juga karena pelepas an proton selama pembentukan struvite [11].

Berdasarkan hasil eksperimen diperoleh residual amoniu m terbaik yaitu 6.006,31; 6.812,76; 6.917,95; dan 8.215,28 $\mathrm{mg} / \mathrm{L}$. Residual amonium 6.006,31 mg/L tidak dipilih sebagai hasil optimum karena menyisakan residual fosfat yang masih besar. Residual amonium 6.917,95 mg/L tidak dipilih sebagai hasil optimum karena membutuhkan penambahan magnesium dalam jumlah besar sehingga membutuhkan biaya yang besar. Sementara itu, residual amonium sebesar $6.812,76 \mathrm{mg} / \mathrm{L}$ yang dicapai pada $\mathrm{pH} 8$ dan rasio molar $\left[\mathrm{Mg}^{2+}\right]:\left[\mathrm{NH}_{4}{ }^{+}\right]:\left[\mathrm{PO}_{4}{ }^{3-}\right]$ tidak dipilih sebagai hasil optimum karena berdasarkan hasil permodelan PHREEQC pada $\mathrm{pH} 8$ dihasilkan struvite yang lebih sedikit daripada pada $\mathrm{pH} 8,2$ dan 8,5. Dengan demikian dari hasil penelitian diperoleh bahwa $\mathrm{pH}$ optimum dalam presipitasi struvite adalah $\mathrm{pH} 8,5$. Meskipun dari hasil permodelan PHREEQC terlihat bahwa pada $\mathrm{pH} 8,5$ dapat terbentuk presipitat lain selain struvite, hal ini dapat diatasi dengan mengatur rasio molar. Tabel 2 menunjukkan hubungan antara $\mathrm{pHdengan}$ residual amonium dan fosfat.

Tabel 2 .

Hubungan Antara $\mathrm{pH}$ dengan Residual Amonium dan Fosfat Rasio Molar $\left[\mathrm{Mg}^{2+}\right]:\left[\mathrm{NH}_{4}{ }^{+}\right]:\left[\mathrm{PO}_{4}{ }^{+}\right]$1,5:15:1

\begin{tabular}{|c|c|c|c|c|}
\hline \multicolumn{5}{|c|}{ Rasio Molar $\left[\mathrm{Mg}^{2-}\right]:\left[\mathrm{NH}_{4}{ }^{+}\right]:\left[\mathrm{PO}_{4}{ }^{3}\right] 1,5: 15: 1$} \\
\hline & Residual & \% Removal & Residual & $\%$ \\
\hline $\mathrm{pH}$ & $\begin{array}{l}\text { Amonium } \\
(\mathrm{mg} / \mathrm{L})\end{array}$ & Amonium & $\begin{array}{l}\text { Fosfat } \\
(\mathrm{mg} / \mathrm{L})\end{array}$ & $\begin{array}{c}\text { Removal } \\
\text { Fosfat }\end{array}$ \\
\hline 8 & $6.812,76$ & 44.53 & 0,53 & 99,99 \\
\hline 8,2 & $11.265,77$ & 8,28 & 2,86 & 99,90 \\
\hline 8,5 & $8.215,28$ & 33,11 & 1,90 & 99,95 \\
\hline \multicolumn{5}{|c|}{ Rasio Molar $\left[\mathrm{Mg}^{2+}\right]:\left[\mathrm{NH}_{4}^{+}\right]:\left[\mathrm{PO}_{4}{ }^{--}\right]$2:15:1 } \\
\hline & Residual & $\%$ Removal & Residual & $\%$ \\
\hline $\mathrm{pH}$ & $\begin{array}{l}\text { Amonium } \\
(\mathrm{mg} / \mathrm{L})\end{array}$ & Amonium & $\begin{array}{l}\text { Fosfat } \\
(\mathrm{mg} / \mathrm{L})\end{array}$ & $\begin{array}{l}\text { Removal } \\
\text { Fosfat }\end{array}$ \\
\hline 8 & $10.704,77$ & 12,85 & 0,49 & 99,99 \\
\hline 8,2 & $10.880,00$ & 11,42 & 5,97 & 99,86 \\
\hline 8,5 & $9.372,37$ & 23,69 & 1,24 & 99,97 \\
\hline \multicolumn{5}{|c|}{ Rasio Molar $\left[\mathrm{Mg}^{2+}\right]:\left[\mathrm{NH}_{4}{ }^{+}\right]:\left[\mathrm{PO}_{4}{ }^{-{ }^{-}}\right]$2,5:15:1 } \\
\hline $\mathrm{pH}$ & $\begin{array}{c}\text { Residual } \\
\text { Amonium } \\
(\mathrm{mg} / \mathrm{L})\end{array}$ & $\begin{array}{l}\text { \% Removal } \\
\text { Amonium }\end{array}$ & $\begin{array}{l}\text { Residual } \\
\text { Fosfat } \\
\text { (mg/L) }\end{array}$ & $\begin{array}{c}\% \\
\text { Removal } \\
\text { Fosfat }\end{array}$ \\
\hline 8 & $11.861,85$ & 3,43 & 0,45 & 99,99 \\
\hline 8,2 & $6.006,31$ & 51,10 & 8,55 & 99,80 \\
\hline 8,5 & $11.300,84$ & 7,99 & 0,30 & 99,99 \\
\hline \multicolumn{5}{|c|}{ Rasio Molar $\left[\mathrm{Mg}^{<+}\right]:\left[\mathrm{NH}_{4}^{+}\right]:\left[\mathrm{PO}_{4}{ }^{-{ }^{-}}\right]$3:15:1 } \\
\hline $\mathrm{pH}$ & $\begin{array}{c}\text { Residual } \\
\text { Amonium } \\
(\mathrm{mg} / \mathrm{L})\end{array}$ & $\begin{array}{l}\text { \% Removal } \\
\text { Amonium }\end{array}$ & $\begin{array}{l}\text { Residual } \\
\text { Fosfat } \\
\text { (mg/L) }\end{array}$ & $\begin{array}{c}\% \\
\text { Removal } \\
\text { Fosfat }\end{array}$ \\
\hline 8 & $6.917,95$ & 43,68 & 0,41 & 99,99 \\
\hline 8,2 & $9.021,74$ & 26,55 & 17,64 & 99,58 \\
\hline 8,5 & $11.441,09$ & 6,85 & 0,20 & 99,99 \\
\hline
\end{tabular}

D. Pengaruh Rasio Molar $\left[\mathrm{Mg}^{2+}\right]:\left[\mathrm{NH}_{4}^{+}\right]:\left[\mathrm{PO}_{4}^{3-}\right]$ terhadap Efisiensi Removal Fosfat dan Amonium

Faktor rasio molar adalah faktor yang sangat berpenganh terhadap kondisi supersaturasi di dalam larutan. Kondisi supersaturasi sangat dipengaruhi oleh konsentrasi masing masing elemen pembentuk struvite [12]. Penambahan magnesium yang berlebih dapat meningkatkan efisiensi removal pada proses ini, akan tetapi juga dapat menurunkan kemurnian struvite yang terbentuk [7]. Semakin besar rasio molar maka efisiensi removal fosfat juga akan semakin besar, akan tetapi kemurnian struvite yang terbentuk akan menurun [13].

Berdasarkan hasil eksperimen diketahui bahwa $\mathrm{pH}$ optimum presipitasi struvite adalah $\mathrm{pH}$ 8,5. Selanjutnya dibuat plot pengaruh rasio rasio molar $\left[\mathrm{Mg}^{2+}\right]:\left[\mathrm{NH}_{4}{ }^{+}\right]:\left[\mathrm{PO}_{4}{ }^{3-}\right.$ ] terhadap efisiensi removal fosfat dan amonium pada $\mathrm{pH} 8,5$. Dari hasil eksperimen diperoleh bahwa rasio molar $\left[\mathrm{Mg}^{2+}\right]:\left[\mathrm{NH}_{4}{ }^{+}\right]:\left[\mathrm{PO}_{4}{ }^{3-}\right]$ optimum adalah 1,5:15:1 dengan efisiensi penyisihan fosfat sebes ar 99,95\% dan residual fosfat $1,9 \mathrm{mg} / \mathrm{L}$ dari semula 4.180,33 $\mathrm{mg} / \mathrm{L}$. Efisiensi penyisihan amonium sebesar 33,11\% dan residual amonium 8.215,28 $\mathrm{mg} / \mathrm{L}$ dari semula 12.282,6 mg/L. Residual fosfat lebih kecil pada rasio molar yang lebih besar, akan tetapi rasio molar yang besar membutuhkan penambahan $\mathrm{Mg}$ yang berlebih sehingga dibutuhkan biaya yang besar. Pada rasio molar yang lebih besar juga dihasilkan residual amonium yang lebih besar. Berdasarkan penjelasan di atas maka ditarik 
kesimpulan bahwa rasio molar optimum dalam eksperimen ini adalah rasio molar $\left[\mathrm{Mg}^{2+}\right]:\left[\mathrm{NH}_{4}{ }^{+}\right]:\left[\mathrm{PO}_{4}{ }^{3-}\right]$ 1,5:15:1. Tabel 3 menunjukkan hubungan antara rasio molar dengan residual amonium dan fosfat.

Pada rasio molar $\left[\mathrm{Mg}^{2+}\right]:\left[\mathrm{NH}_{4}{ }^{+}\right]:\left[\mathrm{PO}_{4}{ }^{3-}\right] \quad$ 1,5:15:1 masih dihasilkan residual amonium dengan konsentrasiyang besar. Secara teoritis, apabila rasio molar $\left[\mathrm{NH}_{4}{ }^{+}\right]:\left[\mathrm{PO}_{4}{ }^{3-}\right]$ adalah $1: 1$, maka seluruh amonium dan fosfat akan habis bereaksi. Akan tetapi, Warmadewanthi dan Liu (2009) menyatakan bahwa kelebihan amonium akan menguntungkan dalam pembentukan struvite karena dapat dipastikan bahwa presipitat yang akan terbentuk dalam reaksi adalah struvite, bukan co-presipitat pengotor lainnya. Selain itu, efisiensi removal $\mathrm{PO}_{4}{ }^{3-}$ meningkat seiring dengan meningkatnya rasio molar $\left[\mathrm{NH}_{4}^{+}\right]:\left[\mathrm{PO}_{4}{ }^{3-}\right]$. Oleh karena itu perlu dilakukan penelitian untuk mengetahui pengaruh rasio molar $\left[\mathrm{NH}_{4}{ }^{+}\right]:\left[\mathrm{PO}_{4}{ }^{3-}\right]$ dalam presipitasi struvite serta pengaruhnya dalam menurunkan residual amonium dan residual fosfat.

Tabel 3.

Hubungan Antara Rasio Molar dengan Residual Amonium dan Fosfat

\begin{tabular}{|c|c|c|c|c|}
\hline $\begin{array}{c}\text { Rasio } \\
\text { Molar } \\
{\left[\mathrm{Mg}^{2+}\right] \text { : }} \\
{\left[\mathrm{NH}_{4}{ }^{+}\right] \text {: }} \\
{\left[\mathrm{PO}_{4}{ }^{3-}\right]}\end{array}$ & $\begin{array}{c}\text { Residual } \\
\text { Amonium } \\
(\mathrm{mg} / \mathrm{L})\end{array}$ & $\begin{array}{l}\% \text { Removal } \\
\text { Amonium }\end{array}$ & $\begin{array}{c}\text { Residual } \\
\text { Fosfat } \\
(\mathrm{mg} / \mathrm{L})\end{array}$ & $\begin{array}{c}\% \text { Removal } \\
\text { Fosfat }\end{array}$ \\
\hline $1,5: 15: 1$ & $8.215,3$ & 33,1 & 1,9 & 99,9 \\
\hline $2: 15: 1$ & $9.372,4$ & 23,7 & 1,2 & 99,9 \\
\hline $2,5: 15: 1$ & $11.300,8$ & 7,9 & 0,3 & 99,9 \\
\hline $3: 15: 1$ & $11.441,1$ & 6,8 & 0,2 & 99,9 \\
\hline
\end{tabular}

\section{KESIMPULAN DAN SARAN}

Kesimpulan yang dapat ditarik dari penelitian ini adalah sebagai berikut:

1. Teknik presipitasi dapat digunakan untuk recovery fosfat dalam bentuk struvite.

2. $\mathrm{pH}$ optimum untuk presipitasi struvite adalah 8,5 dengan rasio molar $\left[\mathrm{Mg}^{2+}\right]:\left[\mathrm{NH}_{4}{ }^{+}\right]:\left[\mathrm{PO}_{4}{ }^{3-}\right]$ untuk pembentukan struvite optimum adalah 1,5:15:1.

Saran untuk penelitian selanjutnya adalah diperlukan penelitian lanjutan untuk mengetahui pengaruh rasio molar $\left[\mathrm{NH}_{4}{ }^{+}\right]$: $\left[\mathrm{PO}_{4}{ }^{3-}\right]$ dalam presipitasi struvite serta pengaruhnya dalam menurunkan residual amonium dan residual fosfat.

\section{UCAPAN TERIMA KASIH}

Penulis mengucapkan terima kasih kepada LPPM ITS dan seluruh pihak yang telah membantu dalam penyelesaian penelitian ini.

\section{DAFTAR PUSTAKA}

[1] J. Shepherd, S. Sohi, and K. V. Heal, "Optimising the recovery and re-use of phosphorus from wastewater effluent for sustainable fertiliser development,"Water Res., vol.94,pp. 155-165, 2016.

[2] B. Ebbers, L. M. Ottosen, and P. E. Jensen, "Electrodialytic treatment of municipal wastewater and sludge for the removal of heavy metals and recovery of phosphorus," Electrochim. Acta, vol. 181 , pp. 90-99, 2015.

[3] I. Zohar, J. A. Ippolito, M. S. Massey, and I. M. Litaor, "Innovative approach for recycling phosphorous from agrowast ewaters using water treatment residuals (WT R)," Chemosphere, vol. 168, pp. 234-243, 2017.

[4] W. de Buck, "Struvite Crystallization and Separation in Digested Sludge," Delft University of Technology, Delft, 2012.

[5] S. Kataki, H. West, M. Clarke, and D. C. Baruah, "Phosphorus recovery as struvite: recent concerns for use of seed, alternative Mg source, nitrogen conservation and fertilizer potential," Resour Conserv. Recycl., vol. 107, pp. 142-156, 2016.

[6] L. Zeng and X. Li, "Nutrient removal from anaerobically digested cattle manure by struvite precipitation," Joumal Environ. Eng. Sci., vol. 5, pp. 285-294, 2006.

[7] J. Wang, J. G. Burken, and X. . Zhang, "Effect of seeding materials and mixing strength on struvite precipitation," Water Environ. Res., vol. 78, pp. 125-132, 2006.

[8] M. Ronteltap, M. Maurer, and W. Gujer, "Struvite precipitation thermodynamics in source-separated urine," Water Res., vol. 5, pp. 977-984, 2007.

[9] A. R. Fitriana, "Penurunan Amonium dan Fosfat Pada Limbah Cair PT Petrokimia Gresik Unit Produksi I dan III,"Surabaya, 2016.

[10] N. Hutnik, A. Kozik, A. Mazienczuk, K. Piotrowski, B. Wierzbowska, and A. Matynia, "Phosphates (V) recovery from phosphorus mineral fertilizers industry wastewater by continuous struvite reaction crystallization process," Water Res., vol. 47, pp. 3635-3643, 2013

[11] P. Stolzenburg, A. Capdevielle, S. Teychené, and B. Biscans, "Struvite precipitation with $\mathrm{MgO}$ as a precursor: application to wastewater treatment," Chem. Eng. Sci., vol. 133, pp.9-15, 2015.

[12] R. Pratama, "Recovery Amonium dan Fosfat Limbah Cair PT Petrokimia Gresik Melalui Proses."

[13] Warmadewanthi and J. C. Liu, "Recovery of phosphate and ammonium as struvite from semiconductor wastewater," Sep. Purif. Technol., vol. 64, pp. 368-373, 2009. 